\title{
O LIVRO QUE [R]EXISTE: A CONFLUÊNCIA DE GÊNEROS COMO SIGNO DA CONTEMPORANEIDADE EM LIVRO DE JOSÉ LUÍS PEIXOTO
}

THE BOOK THAT [R]EXISTS: THE CONFLUENCE OF GENRES AS A SIGN OF CONTEMPORANEITY IN LIVRO BY JOSÉ LUÍS PEIXOTO

Diana Navas*

José Luiz Cordeiro Dias

Tavares**
* diana.navas@hotmail.com

Doutora em Literatura Portuguesa pela Universidade de São Paulo professora do Programa de Estudos Pós-Graduados em Literatura Crítica Literária da PUC-SP (São Paulo - SP).

**jltavares2016@gmail.com

Mestrando do Programa de Estudos Pós-Graduados em Literatura e Crítica Literária da PUC-SP (São Paulo - SP).

RESUMO: O presente estudo, que assume como corpus o romance Livro (2012), de José Luís Peixoto, almeja apresentar a mance Livro (2012), de Jose Luís Peixoto, almeja apresentar a confluência de gêneros que se observa na composição desta obra, evidenciando como seu hibridismo mantem estreito diálode uma breve reflexão acerca das marcas da atual ficção contemporânea portuguesa - a confluência dos gêneros, a metaficção, a polifonia e a paródia - , apresentamos, a seguir, o romance de Peixoto, evidenciando como nele os gêneros literarios e nao-lide um livro híbrido. Nessa obra, não apenas a poesia insere-se no romance, mas o ensaio e outros gêneros perpassam a narrativa, tornando o espaço romanesco plural e heterogêneo. Ao final demonstramos como a confluência de gêneros neste romance está em consonância com o atual cenário contemporâneo, também marcado pela multiplicidade e heterogeneidade.

PALAVRAS-CHAVE: contemporâneo: José Luís Peixoto: Livro; gênero; hibridismo.
ABSTRACT: The present study, which takes as its corpus the novel Livro (2012), by José Luís Peixoto, aims to present the confluence of genres that is evident in the composition of this work, pointing how its hybridity maintains a close dialogue with the contemporary context. Starting from a brief reflection on the marks of contemporary Portuguese fiction - the confluence of genres, metafiction, polyphony and parody -, we present, next Peixoto's novel, evidencing how literary and non-literary genres Peixe present in the novel, promoting the construction of a hybrid book. Finally, we c book. Finally, we demonstrate how the contluence of genres in his novel is in consonance with the current contemporary scenario, also marked by multiplicity and heterogeneity.

KEYWORDS: contemporary; José Luís Peixoto; Livro; gender hybridity. 


\section{BREVES CONSIDERAÇÕES SOBRE O ROMANCE}

\section{PORTUGUÊS CONTEMPORÂNEO}

O romance, gênero que tem acompanhado esteticamente as manifestações culturais do ocidente desde o século XVIII (WATT, 1990), mantém estreito diálogo com o contexto histórico-social contemporâneo, refletindo as variadas e vertiginosas transformações de nosso tempo. Múltiplo, assim como o cená rio em que esta mos inseridos, o romance busca retratar a pluralidade da vida, seja ela a coletiva, seja a individual, com o homem olhando para a sua interioridade em busca de respostas para suas inquietações e conflitos.

A expressiva - seja em termos qualita tivos ou quantitativos - ficção contemporânea portuguesa constitui, assim, na expressão de Calle-Gruber (1989), um "espelho privilegiado do mundo". Fruto de uma consciência atenta aos problemas político-sociais e ta mbém às estra tégias empregadas na construção literá ria, o atual romance português, conforme assegura Gomes, é marcado pela combatividade, revelada por meio da crítica que estabelece não apenas em relação à realidade, ao contexto, mas, ta mbém, no que concerne ao universo do romance, aos mecanismos da ficção. "Em outras palavras, o romance português contemporâneo não só fa rá o inventário crítico da situação político-econômica portuguesa, como também fará um inventário crítico da linguagem, do modo de narrar e do compromisso do escritor com a realidade" (GOMES, 1993, p. 84).

Conscientes, portanto, de que tão importante quanto o contexto a ser analisado é ta mbém o modo como tal contexto é focalizado, os escritores portugueses contemporâneos - dos quais destaca mos José Sara mago, António Lobo Antunes, Gonçalo Tavares, Inês Pedrosa, Valter Hugo Mãe, José Luís Peixoto - empreendem a crítica ta mbém em relação ao próprio fazer literário. O romance revela-se, assim, essencialmente crítico de uma forma que privilegiava modos de ser e de ver tradicionais, impedindo um descompasso entre a proposta temática revolucionária dos romances e o instrumental empregado em sua construção.

Ana Paula Arnaut, uma das mais reconhecidas estudiosas do romance português contemporâneo, apresenta o que considera ser as principais tendências desta atual produção romanesca portuguesa:

Da nova literatura sobressaem os seguintes aspectos: a mistura de géneros e a decorrente fluidez genológica, num culto ostensivo e quase sempre subversivo; a insistente e crescente polifonia - em algumas situações a tocar as fronteiras do indecidível, da fragmentação e da (aparente) perda de narratividade; os exercícios metaficcionais, já presentes em 
romances cómicos e satíricos do século XVIII, mas agora renovados em grau e qualidade e alargados da escrita da história à re-escrita da História. Sublinhe-se, a propósito, o modo como se processa a recuperação do passado, a imposição da paródia como elemento de fundamental importância para a deslegitimação das grandes narrativas que, num entendimento que nos parece pertinente, estendemos a códigos genológicos e periodológicos. (ARNAUT, 2002, p. 131)

A confluência de gêneros, a metaficção, a polifonia e a paródia não são, certamente, aspectos ficcionais inéditos. Advém daí o fato de Arnaut afirmar que à literatura contemporânea se ajusta a máxima non nova, sed nove (não coisa nova, mas de uma nova maneira). Esta mos diante de uma produção literária em que a "implementação do novo traduz-se, ainda, em relações simultâneas de oposição e de permanência de características já existentes em passados mais ou menos próximos ou mais ou menos remotos" (ARNAUT, 2002, p. 131). Dito de outra maneira, podemos verificar que a literatura portuguesa contemporânea estabelece uma atitude relacional com vários passados que, de acordo com Arnaut, de modo distinto, ecoarão em nosso presente. Romances nos quais, ainda que haja o resgaste de elementos já conhecidos, operam-se transgressões, de modo que a atual produção literária portuguesa se revela marcada tanto pela continuidade quanto pela ruptura.
É este caminhar para o futuro, sem, entretanto, deixar de manter diálogo com o passado, bem como o intrínseco diálogo que o gênero roma nesco estabelece com o cenário contemporâneo o que nos interessa no presente estudo. Almejamos, a partir da leitura de Livro, de José Luís Peixoto, uma das mais jovens - e, ao mesmo tempo, mais prolíficas - vozes da atual literatura portuguesa, demonstrar como a confluência de gêneros que se evidencia nesse romance estabelece intrínseca relação com o contexto contemporâneo em que se insere.

\section{A CONFLUÊNCIA DAS LETRAS E OS AZULEJOS}

Livro é o nome do romance de José Luís Peixoto lançado em Portugal em 2010 sobre o qual este texto se debruça. As marcas da leitura desta obra se tornam potencialmente mais nítidas caso a referência ao contexto histórico português no qual o romance se insere não deixe de ser considerada pelo leitor. Referimo-nos, aqui, ao período da ditadura salazarista que se estendeu de 1933 a 1974 em Portugal, durante o qual alguns registros cronológicos ao longo do romance são pontuados, como se fossem gestos do autor não apenas para marcar o tempo, mas, ta mbém, para manter viva a memória e o valor da cidadania na história da huma nidade.
EM TESE
BELO HORIZONTE
v. 26
N. 2
MA10-AGO. 2020
NAVAS; TAVARES. 0 livro que [r]existe: a confluência de gêneros [...]
p. $283-296$

Teoria, Crítica Literária, outras Artes e Mídias 
Livro é ta mbém uma obra que fala do resistir, [r] existir, re-existir, existir de novo e uma vez mais, como a expectativa daquele povo que, por décadas, buscou resistir ao regime que lhes foi imposto mantendo viva a esperança de vir a existir com a utonomia, talha ndo sua própria subjetividade, livres de uma estrutura assimétrica de poder. Este romance de José Luís Peixoto traz uma história que percorre o tempo através de diferentes personagens com diversas narrativas de vida, confluentes entre si e trazidas à cena como os ta mbém diversos gêneros literários que confluem ao longo das páginas em alusão à marca plural da contemporaneidade.

O romance se inicia no a no 1948 com o seguinte enunciado: "A mãe pousou o livro nas mãos do filho". (PEIXOTO, 2012, p. 9). Uma frase que certamente não está assim escrita e disposta ao acaso na primeira página. Com este recurso, Peixoto parece arremessar o leitor em uma história já em movimento, sem oferecer informações prévias sobre quem são essa mãe e seu filho exatamente para instigar a curiosidade do leitor. Com poucos elementos - uma mãe, seu filho e um livro - o autor inaugura a narrativa e os dispõe em um arranjo que confere ao objeto-livro um possível pape de mediação na história do filho a partir daquele momento. Naquela cena, algo se transmite da mãe para o filho que se chama Ilídio. Algo a mais do que apenas um livro, como se fosse um legado que se transmite como um sinal de resistência para permanecer vivo que nos remete ao que fez Aquiles na luta entre gregos e troianos descrita na Ilíada. Curiosamente, o livro que Ilídio recebe da mãe é o mesmo que ele, já adolescente, irá oferecer a Adelaide, com quem, mais tarde, terá um filho cujo nome é, inusitadamente, o nome deste romance: Livro.

Em sua aula inaugural no Collège de France, Barthes pergunta se o idioma de Dante é o latim ou o tosca no ou, ainda se o idioma francês seria o clássico, o moderno, o idioma falado ou o escrito e conclui que a resposta está na verdade do desejo e que as sociedades deveriam proporcionar aos cidadãos o luxo da existência de tantas línguas qua nto houvesse de desejos. Para ele, as palavras não são simples instrumentos, mas sim projeções, explosões, vibrações, saberes. A escritura faz do saber uma festa, afirma Barthes. $\mathrm{Na}$ semiologia da mensagem, conclui ele, há desejos, temores, ternuras, protestos, desculpas, agressões etc. Trata-se da música da qual a língua ativa é feita. (BARTHES, 2019, p. 21-26; 33-34). Em Livro, Peixoto nos apresenta um mosaico de gêneros, como os diversos acordes na escritura dessa música e, a certa altura, dirige-se ao leitor perguntando se um nome é suficiente. "Não é", ele mesmo responde. (PEIXOTO, 2012, p. 243). Seu texto transborda e se desdobra em múltiplas palavras e personagens, trajetórias 
que circulam por diferentes países em vilas de interior ou capitais, expressando-se em vocabulá rios rurais e urbanos, exibindo múltiplos desejos que cruzam fronteiras, chancelando os limites borrados próprios da confluência de gêneros que se faz presente como uma das marcas da literatura na contemporaneidade.

$\mathrm{Na}$ diversidade dos múltiplos a fetos, como proposto por Barthes (2019), assenta-se o disperso pulsional contemporâneo, que desconstruiu referências identitárias, esgarçou fronteiras e colocou o homem em uma posição de afirmação de sua própria subjetividade. Distante da assimetria hierárquica da modernidade, o homem contemporâneo buscou novas saídas para a construção de sua subjetividade, trazendo outros arranjos de confluência para suas aspirações, resultando, assim, em um estado de permanente [re] construção. Um luxo barthesiano que legitima a diversidade de línguas e desejos ao qual Peixoto se lança ta mbém, legitimando diferentes gêneros literários em sua escrita e que confluem para deleite do leitor nas páginas de sua obra Livro. Em sua edição brasileira de 2012, não por acaso a capa do romance nos traz uma profusão de letras que também confluem de tal forma que nos remetem à imagem dos azulejos, um dos signos da cultura portuguesa, articulando os registros estéticos da escrita com os referenciais da cultura.

\section{DESACOMODANDO LUGARES MARCADOS}

\section{O LIVRO HÍBRIDO}

Retomando o que foi apresentado por Arnaut no tocante à tendência da ficção portuguesa contemporânea de transitar entre a manutenção e a desestabilização de paradigmas, verifica mos que, nos a tua is roma nces portugueses, há uma espécie de esvaecimento dos limites que delimitam e organizam os gêneros tradicionais. Neste panorama, deparamo-nos com obras que não necessaria mente se encaixam em enquadramentos fixos de gênero, de tal forma que outras modalidades de escritura passam a ocupar espaço no romance, subvertendo os padrões já estabelecidos, exatamente como se observa no cotidiano contemporâneo das cidades, fora do espaço literá rio, gerando um profícuo estado de tensão entre permanência e oposição.

Podemos, nos romances portugueses contemporâneos, dos quais Livro é um exemplo, olhar com mais atenção para a questão da mistura de gêneros que confluem na escrita contemporânea e que se articula com a noção de hibridismo que engloba diferentes gêneros tanto literários como artísticos, abrindo o leque para as diversas possibilidades de expressão do homem, suas inquietudes e afetos. Garantese, assim, a existência de um espaço de notoriedade tanto à forma quanto ao conteúdo da obra. A maneira de contar a história ganha tanto destaque como aquilo que se conta na

Teoria, Crítica Literária, outras Artes e Mídias 
história e, além disso, evidencia flancos abertos nas formas estruturadas e estanques dos gêneros literários tradicionais. Trata-se aqui do desafio da desconstrução de um discurso consagrado pela força do tempo e do hábito que - em consonância com o contexto contemporâneo, no qual se intensifica a diluição de fronteiras -, possibilita outras forma de expressão. Neste processo, perde-se a segurança de um contorno que desenha e reforça as classificações - dentre elas, a dos gêneros literários -, porém lança-se a obra e seus leitores em um espaço fecundo, ainda que instável, e que reproduz o panora ma sociocultural a tual, o qual dilui certezas e desafia o sujeito a ocupar um lugar de autonomia, menos alienado de imagos de referência identitá ria. Como em uma chaga exposta, surge a tensão entre o conformismo da permanência e as outras perspectivas que buscam espaço para existir, tributá rias de insatisfações com o enquadre estabelecido, permitindo-se aludir aqui à dinâmica vivida pelo povo português em sua história recente, conforme já comentado.

Como indicado pela própria denominação deste recurso da escrita, na confluência de gêneros não há vínculo exclusivo da obra a um só gênero literário. Em uma mesma obra, como ocorre em Livro, podem ser reconhecidos diferentes modalidades de escrita que desestabilizam o pacto literário entre a obra e os leitores à medida que não há mais possibilidade ta mpouco interesse em classificar a obra dentro de um enquadre tradicional de gêneros (PERRONEMOISÉS, 2005). Torna-se, aqui, válido ressaltar que, ainda que o hibridismo não seja um fenômeno novo, exclusivo do contemporâneo, conforme já justificado neste estudo pelas palavras de Arnaut (2002), a mescla de gêneros intensifica-se em nosso contexto, marcado, ta mbém ele, pela clara desestabilização de fronteiras e consequente pendor às fusões, às (con)fluências. Desta maneira, em uma mesma obra participam diversos gêneros - sejam eles literários ou não - com as características que o determinam, assim como se verificam, ta mbém, fenômenos va riados de estilos Ensaio, ficção, a utobiografia, relatos ou diários, pesquisas históricas, fotografias, desenhos, documentos e outros gêneros textuais podem estar presentes em um único texto dito híbrido, porém sem necessariamente interferir com o eixo narrativo. Assim, a rigidez do estatuto ficcional da narrativa se desconstrói e dá espaço para outras modalidades de articulação entre a obra, que tem sua imagem de totalidade dispersada em um tecido ilimitado de conexões, associações, fragmentos, textos e contextos. Ao não se fixar em um único gênero literário, o autor ta mbém convida o leitor a repensar suas chaves de leitura de mundo com a perspectiva de ampliá-las para possibilidades diversas. $\mathrm{O}$ tênue delineamento das fronteiras entre o real e a ficção permite que estas categorias passem de uma relação 
dicotômica de oposição para uma dinâmica de interatividade que não necessariamente se esgota na obra em si, mas sim aponta para a abertura de um produto em construção.

Peixoto escreve Livro recusando os limites impostos pelas marcas habituais dos estilos formais consagrados pela tradição. São diálogos sem travessão; parágrafos que se iniciam com a letra maiúscula das primeiras palavras que só se completam após espaços em branco correspondentes a duas ou três linhas ou então iniciados por numera is irregularidades do intervalo entre diferentes parágrafos ao longo das páginas; capítulos iniciados por datas entre parênteses, enqua nto outros apenas iniciam sem qualquer notação; palavras circunscritas por círculos sem maiores explicações; asteriscos ou palavras soltas entre parênteses inseridas no meio dos capítulos, dentre outras liberdades de estilos gráficos variados empregados pelo autor e que parecem colaborar para anunciar e sustentar o hibridismo da confluência de diferentes gêneros literários e não literários ta mbém presentes nesta obra.

Quanto ao hibridismo em Livro, pode-se identificar a presença de diferentes gêneros literários. De acordo com Colonna (apud AMORIM, 2016, p. 452), em alguns momentos, a escrita em Livro se assemelha à forma narrativa autoficcional fantástica, na qual o escritor está no centro do texto, como uma autobiografia, porém transfigurando sua existência e a sua identidade numa história indiferente à verossimilhança:

No chão, destroço, atrás da sombra de uma rocha, estava o corpo de um dos homens que viera na parte de trás da caminhoneta. Tinha o rosto e os olhos atravessados por riscos de garras, tinha a pele rasgada por vincos fundos, cravados na carne. Tinha o rosto esfarrapado. Faltava-lhe um dos lados do pescoço, comido, arrancado à dentada. Estava branco, como se não fosse feito de pessoa, como se fosse uma forma de areia fina. Não escorria sangue das feridas. Estava seco, gelado. (PEIXOTO, 2012, p. 98)

Outros trechos nos remetem a obras de ficção científica, como na passagem de Galopim que, estava claro, "não era um homem mas tinha corpo" (PEIXOTO, 2012, p. 30) ou quando Ilídio se mistura com um pombo, como se fosse uma fusão possível na natureza e lemos que "[a mbos] não sabiam para onde iam, onde estavam" (PEIXOTO, 2012, p. 110).

A confluência entre a prosa e a poesia também é notável em Livro. Evidenciamos, ao longo de todo o texto, a recorrência a recursos usualmente empregados na poesia, como uma certa musicalidade na escrita, além de metáforas 
dispersas ao longo do texto, remetendo-nos à estrutura de uma prosa poética. Exemplo disso é a alusão ao pós 25 de abril, construída por meio do trabalho com e na linguagem, em que as imagens da primavera e do inverno apontam, poeticamente, para a ditadura e liberdade do povo português:

Uma breve teoria: há certos movimentos que apenas são possíveis depois do início da primavera. Durante a invernia, o corpo esquece-os, mingua, endurece como as árvores. Em maio, o corpo recorda esses movimentos, julga reaprendê-los e, ao fazê-lo, redescobre a sua verdadeira natureza. É por isso que se fala de renascer na primavera, é por isso que as pessoas se apaixonam, e é por isso que crescem as plantas. Esses movimentos são simples, todas as pessoas sabem fazer. Ao serem empreendidos, dão lugar a multidões desgovernadas de sequências que, no fim da sua ação, acedem o sol. (PEIXOTO, 2012, p. 13)

A incorporação de outros gêneros não se limita, no romance em questão, aos literários. Códigos até então considerados não ficcionais pela tradição - como é o caso do ensaio, por exemplo - são trazidos para a cena da composição literária. Na segunda parte de Livro, o texto ficcional ganha caráter experimental, tornando-se uma espécie de ensaio que assume como foco o próprio fazer literário e que antecipa possíveis críticas à obra:

A segunda parte consiste num desequilíbrio estrutural injustificado, experimentalismo fora de tempo. É nesse ponto que o romance a tinge níveis intoleráveis de arrogância. Para lá das constantes referências a autores que ele, nitidamente, desconhece, num exercício fútil de name-drop, esperteza de google, o clímax de insensatez é alcançado numa espécie de autocrítica que, fazendo parte do romance, se refere ao próprio romance. A autorreferencialidade e o pós-modernismo têm costas largas. (PEIXOTO, 2012, p. 242-243)

Ainda no que tange à presença de gêneros não-literários, podemos destacar a inserção, em meio à narrativa literária, do método $\mathrm{N}+7$ da OuLiPo (Oficina de Literatura Potencial):

$\mathrm{N}+7=$ A cascavel estava vazia quando saí do camarim.

$\mathrm{N}+6=\mathrm{A}$ cascata estava vazia quando saí da camarata

$\mathrm{N}+5=\mathrm{O}$ cascalho estava vazio quando saí do camarão.

$\mathrm{N}+4=$ A casca estava vazia quando saí da câmara. 
$\mathrm{N}+3=\mathrm{O}$ casamento estava vazio quando saí do camaleão.

$\mathrm{N}+2=\mathrm{O}$ casal estava vazio quando saí do camafeu.

$\mathrm{N}+1=$ A casaca estava vazia quando saí da camada.

$\mathrm{N}+0=$ A casa estava vazia quando saí da cama. (PEIXOTO, 2012, p. 259)

Tal método, que consiste em criar um texto, substituindo todo substantivo pelo sétimo que aparecer após ele no dicionário, e que foi elaborado por um grupo que sugere a libertação da literatura por meio de experimentos diversos, ao ser inserido em meio às páginas de um romance contribuem para promover a desautomatização do olhar leitor e a quebra de suas expectativas.

As referências intertextuais a reconhecidos autores que escreveram em diferentes gêneros literários são também notáveis em Livro. Elas vão de Homero a Dylan Thomas, Sylvia Plath, Proust, Virgínia Woolf, Camus, Ja mes Joyce, Marguerite Yourcenar, Mark Twain, Kafka, Hemingway, George Orwell, Thomas Mann, Flaubert, D. H. Lawrence, Balzac, Dostoievski, Faulkner, Alexandre Dumas, Sartre, Mary Shelley, Emily Dickinson, Ezra Pound, Shakespeare e outros, indicando a conexão com obras de diferentes épocas e nacionalidades, enquanto, ao mesmo tempo, insere a obra em uma rede de textos com os quais o autor mostra ter mais do que simples afinidades. Ao elencar todos esses nomes, Peixoto faz uma clara reverência aos mestres da literatura que arrebatam o leitor, que se sente impelido a emocionar-se junto a ele ao relembrar trechos de obras emblemáticas desses icônicos escritores.

Povoam, ainda, as páginas do romance listas (PEIXOTO, 2012, p. 202, 232), questioná rios sugeridos aos leitores, assim como trechos com lacunas a serem por eles preenchidas:

Indique os seguintes dados

Nome da sua mãe

Autor/a mais antigo que já leu

Título do último livro que terminou de ler (sem contar com este, que ainda não terminou de ler)

Primeira coisa que fez hoje ao acordar (infinitivo) [...]. (PEIXOTO, 2012, p. 221)

Preencha os espaços em branco com as respostas anteriores: Se algum dia tiver uma filha, hei-de chamar-lhe

(1), como a minha vó. Não hei de obrigá-la a ler

(2), lerá apenas aquilo que escolher. Se encontrar um exem- 
plar de

(3) na sua mesinha-de-cabeceira, saberei que the transmiti a procura, o desejo de compreender o mundo. À margem disso, havemos de (4) juntos [...] (PEIXOTO, 2012, p. 223)

Desta forma, o leitor, peça central para a (re)construção desse puzzle em que se constitui o romance, é convidado a responder e contribuir com a construção conjunta da obra, sendo recorrentemente atentado para o caráter de artefa to habilmente construído do texto literário.

Como pode ser observado a partir dos exemplos citados, as fronteiras entre os gêneros diluem-se de maneira intensa na contemporaneidade. Poesia, prosa, ensaio, autobiografia, dentre outros - seja m eles literá rios ou não -, figuram lado a lado, nas páginas do romance, sem que, no entanto, o eixo narrativo se dilua: a história de Ilídio com conflitos e desejos movidos pela pulsão de vida em articulação com os sentimentos do povo que buscou resistir em meio à tragédia da ditadura ansiando pela liberdade em oposição à tirania de um regime político de esmaga mento e opressão. Nem um gênero nem outro isoladamente, mas sim hibridamente mesclados na mesma escrita, o que promove uma equiparação de valor entre eles e, consequentemente, a ruptura com a supremacia do discurso literário. Essa multiplicidade acaba por figurar como uma espécie de reflexo da realidade, também composta discursivamente, por discursos variados e confluentes.

Finalmente, especulando sobre a possível motivação do autor para a elaboração da trama que sustenta boa parte do arcabouço proposto para essa obra, parece-nos que o embaralhamento das fronteiras entre diversos gêneros literários se faz metáfora nas viagens e nos deslocamentos que atravessam e diluem fronteiras políticas, culturais e linguísticas narradas nas páginas desse livro. Cruzar essas bordas, justapondo diferentes realidades e geografias, remete-me simbolicamente ao recurso do hibridismo de gêneros utilizados por José Luís Peixoto e que confluem no ato de escritura de Livro.

\section{ALGO SE INSERE NO TEMPO DE CHRONOS}

Podemos considerar que as variadas formas de expressão cultural, dentre as quais se inclui a literatura, são arquiteturas simbólicas em vínculo com as dinâmicas socia is vividas pelos autores que de alguma forma são atravessados em sua singularidade, tornando-se motivados a colocar no papel o que os inquieta. Trata-se aqui, portanto, da possibilidade de considerar a literatura como um dispositivo que está para mais além de um simples a to de leitura e interpretação pois articula-se proficua mente com a cultura da qual emerge e, potencialmente, captura o leitor por alguma via peculiar de

Teoria, Crítica Literária, outras Artes e Mídias 
identificação, não raramente inconsciente, e que de alguma forma nele ecoa como um vocativo que faz sentido em algum aspecto de sua trajetória pessoal e em permanente diálogo com o contexto histórico-social em que se insere.

O percurso acidentado e turbulento próprio da natureza humana se faz presente na dinâmica literária ao longo dos séculos, como se a escrita pudesse de alguma forma ser um registro especular do que se passa na cultura. A literatura, como uma das maneiras de traduzir a construção da subjetividade, constitui-se como um potente recurso de significação visceralmente dependente da linguagem, instaurando uma eloquente possibilidade de representação do homem no mundo.

Em Delírios e sonhos na Gradiva de Jensen, Freud (2015, p. 16) a firma que escritores criativos são aliados muito valiosos, cujo testemunho deve ser tido em alta conta, pois costumam conhecer toda uma vasta gama de coisas entre o céu a terra com as quais a nossa filosofia ainda não nos deixou sonhar (a clara alusão é aqui a Hamlet). Por esse motivo, segue ele, escritores estão bem adiante de nós, gente comum, no conhecimento da mente, já que se nutrem em fontes que ainda não tornamos accessíveis à ciência. Alguns anos mais tarde, Lacan, em seu movimento de retorno a Freud, confirma essa observação ao enunciar que o "o inconsciente é, em seu fundo, estruturado, tra mado, encadeado, tecido de linguagem” (LACAN, 1981, p. 135).

Cem anos depois de Proust, o tempo contemporâneo flui ao sabor de novas formas de subjetivação sob um imperativo de consumo tão voraz e veloz que dificultaria a devida apreciação do chá de sua xícara, com o tempo e a quietude necessários para que os aromas próprios da infusão pudessem ser saboreados. Durante muito tempo, e até o início do século $\mathrm{XX}$, as estruturas socia is garantiram um modelo vertical no qual a hierarquia per se era legitimada. Após o final da Segunda Guerra Mundial, surgiram diversos movimentos de inconformismo. Seja nos protestos urbanos de maio de 68 em Paris ou nas canções de Woodstock em agosto de 69 , tais manifestações cla mavam por transformações das relações sociais almejando a passagem da autoridade chancelada pelo modelo hierárquico para um cenário de menor assimetria e maior liberdade. Os movimentos que buscavam migrar da verticalidade para a horizontalidade interferira m no modo de funcionamento coletivo e, portanto, no papel das estruturas até então garantidoras da construção identitária. Ampliavam-se as formas possíveis para o advento do sujeito e suas possibilidades de inserção no tecido social. No final da década de 60, no Brasil, Caetano e os Mutantes anunciavam que era proibido proibir, Hélio Oiticica apresentava seus

EM TESE BELO HORIZONTE $\quad$ v. $26 \quad$ N. 2 MAIO-AGo. 2020 NAVAS; TAVARES. 0 livro que [r] existe: a confluência de gêneros [...]

Teoria, Crítica Literária, outras Artes e Mídias 
parangolés e Zé Celso reinventava a arte dramática com o Tea tro Oficina. Era o final de um período marcando a mudança do tempo que passa a ser considerado contemporâneo. Em Portugal, essa passagem ta mbém ocorreu no mesmo período, culmina ndo com a espera nça trazida com a Revolução dos Cravos em 1974.

Na sequência linear do tempo quantitativo e mensurável de Chronos, algo qualita tivo se inscreveu nesse lapso temporal. Insta urou-se uma dinâmica do aqui e agora, ansiando pela ausência de limites e de impedimentos sustentada pela variedade, facilidade, rapidez e descartabilidade de opções, criando uma arena de permanências impermanentes, questionando a perenidade dos fatos até então estabelecidos. Nesse movimento, a família patriarcal, assim como as instituições educaciona is e religiosas, além de outros organizadores socia is, como os vínculos trabalhistas ou ideologias políticas que operava m como referências identitárias, foram progressivamente ressignificados. Novas técnicas reprodutivas ta mbém surgiram e se difundiram. A maior disponibilidade dos recursos contraceptivos trouxe a possibilidade de dissociação entre sexo e procriação. Com esse movimento, reposicionou-se a perspectiva do prazer, que ingressou nessa equação, conduzindo à a utonomia do sujeito em relação ao próprio corpo. Trata-se de um momento transformador que necessariamente se fez encenando uma bandeira de liberdade, diversidade e oxigenação. É nessa cena social que a literatura também se re-inscreve, resiste, $[r]$ existe e re-existe, desenhando uma outra maneira de ocupação simbólica, em um registro ta mbém plural que escapa da hierarquia classificatória dos gêneros literários ditos "tradicionais" e se autoriza em uma escrita híbrida que confere à confluência de gêneros um espaço de reconhecimento literário, garantindo-lhe o esta tuto de um valor estético contemporâneo em construção. Livro, destarte, revela-se como uma elaboração em que nitidamente se sobressai o trabalho estético de experimentação e o consciente labor escritural, que, no entanto, longe de se constituir como um mero exibicionismo da capacidade técnica de seu escritor, mantém estreito diálogo com seu contexto de histórico-cultural de produção.

\section{(IN)CONCLUSÃO}

Quadro ainda em construção e, portanto, em constante atualização, o romance contemporâneo português é já marcado por uma multiplicidade de temas, conteúdos, estilos e formas narrativas que nos permitem caracterizá-lo como uma produção plural e prolífica. Assumindo um caráter combativo, em termos temáticos e estruturais, a literatura portuguesa contemporânea estabelece um intrínseco diálogo com o seu contexto histórico-cultural, encontrando na confluência de gêneros, na metaficção, na polifonia e 
na paródia - recursos não novos, mas empregados de uma nova maneira - formas de questionar a tradicional forma de escrever romances e, por conseguinte, das formas de ver e ser tradicionais.

Dentre as vozes que ecoam nesse cenário está a de José Luís Peixoto, escritor que, apesar de jovem, é já bastante reconhecido e premiado, e que nos convida, em Livro, a refletirmos acerca da mescla de gêneros no espaço do romance. Conforme pudemos observar, sua narrativa espraia-se pela prosa, poesia, ensaio, a utobiografia, gêneros esses colocados ao lado de outros não consagrados pela tradição - listas, questionários, notas, apontando para a multiplicidade de que é constituído, na contempora neidade, o texto literário.

Libertando o texto das rígidas classificações, das a marras dos gêneros literários, Peixoto oferece-nos uma narrativa híbrida que, sem perder seu fio condutor, apresenta-se como uma colcha de retalhos, construída a partir de diferentes gêneros discursivos, estratégia essa em estrito diálogo com o contexto histórico-cultural em que se encontra inserida. Em um cenário marcado pela pluralidade, pela diversidade, pelo híbrido, a multiplicidade e heterogeneidade de discursos em Livro figuram como reflexo de uma realidade, ta mbém discursiva, e constituída por discursos variados e confluentes, reforçando, portanto, o diálogo profícuo e necessário que a literatura mantém com o seu contexto.

\section{REFERÊNCIAS}

AMORIM, S. Livros e vidas: atravessando fronteiras em Livro, de José Luís Peixoto, e Biografia involuntária dos amantes, de João Tordo. Letrônica, Porto Alegre, v. 10, n. 1 , p. 443-458, jan.-jun. 2017

ARNAUT, A.P. Post-modernismo no romance português contemporâneo. Fios de Ariadne. Máscaras de Proteu. Coimbra: Almedina, 2002.

ARNAUT, A.P. Post-modernismo: o futuro do passado no romance português contemporâneo. Via Atlântica, São Paulo, 2010, n.17, jun./2010

BARTHES, R. Aula. São Paulo: Cultrix, 2019

FREUD, S. O delírio e os sonhos na Gradiva de W. Jensen. In: Obras completas de Sigmund Freud. vol. 8. São Paulo: Companhia das Letras, 2015. p. 13-122. [1907].

GOMES, A. C. A voz itinerante: ensaio sobre o romance português contemporâneo. São Paulo: EDUSP, 1993 
LACAN, J. Le Séminaire, Livre III: Les Psychoses. Paris: Seuil, 1981.

NAVAS, D. Figurações da escrita. São Paulo: Scortecci, 2013.

PEIXOTO, J. L. Livro. São Paulo: Companhia das Letras, 2012

PERRONE-MOISÉS, L. Texto, crítica, escritura. São Paulo: Martins Fontes, 2005.

WATT, lan. A ascensão do romance: estudos sobre Defoe, Richardson e Fielding. Trad. de Hildegard Feist. São Paulo:

Companhia das Letras, 1990

Recebido em: 15-07-2020 Aceito em: 17-01-2021 